\title{
Re-examining the ECB's two-pillar monetary policy strategy: Are there any deviations during and the pre- financial crisis periods?
}

\author{
Ahmad Hassan Ahmad' ${ }^{1}$ Stephen Brown'
}

Published online: 10 May 2016

(C) The Author(s) 2016. This article is published with open access at Springerlink.com

\begin{abstract}
This paper addresses the extent to which the ECB rate setting responded to inflation and monetary growth in the run up to, and during, the financial crisis of the late 2000s. The analysis covers the period between 1999:01 and 2013:12, split into pre-crisis and financial crisis periods using a structural break test. In addition, a number of specifications are examined, including those in which only positive or negative policy rate changes are used as the dependent variable. An ordered probit model is used as it is deemed more appropriate for modelling discrete economic behaviour, such as policy rate changes, than continuous time series methods. The results from the pre-crisis period show that, although the monetary aggregate was significant in models that incorporate all the policy changes, but when considering just positive policy rate changes, the coefficient for monetary growth is not only small, but also statistically insignificant. Hence, this casts doubt on the extent to which monetary growth influenced the ECB policy rate decisions prior to the financial crisis. The monetary growth coefficients for the crisis period are also found to be insignificant. However, unlike during the pre-crisis period, the coefficient for inflation is found to be both positive and statistically significant, thus confirming qualitative perceptions that the ECB prioritised its price-stability mandate over concerns that the Euro Area sovereign debt crisis.
\end{abstract}

Keywords ECB · Monetary policy · Financial crisis

JEL Classification E02 $\cdot$ E42 $\cdot$ E61

Ahmad Hassan Ahmad

A.H.Ahmad@lboro.ac.uk

1 School of Business and Economics, Loughborough University, Leicestershire LE11 3TU, UK

2 Department of Economics, University of Bath, Claverton Down, Bath BA2 7AY, UK 


\section{Introduction}

The ECB's monetary policy strategy hinges on a numerical definition of price stability and a two-pillar method of analysing risks to price stability. Price stability is defined by the ECB Governing Council as a growth rate in the Harmonised Index of Consumer Prices (HICP) of close to, but below, $2 \%$. This is to be upheld over the medium-term. The two-pillar strategy refers to economic (Pillar 1) and monetary (Pillar 2) analysis that informs policy rate decisions made by the Governing Council. ${ }^{1}$ Pillar 1 takes into account the main factors that affect price developments in both the short- and medium-term and its main emphasis is on real economic activity. Pillar 2 is mainly concerned with the long-run relationship between money and prices and, therefore, undertakes comprehensive analysis of monetary and credit developments in the Area. Since its relegation to pillar 2, the main emphasis of the monetary analysis has been on the fundamentals of the monetary aggregates, such as the role of cross-border portfolio flows.

Many economic commentators have argued that central banks are partly to be blamed for the financial crisis, with allegations that short-term price stability was favoured at the expense of excessive debt growth. For example, in the Euro Area, despite the ECB's Pillar 2 strategy, it has been argued that too little was done to curb credit growth prior to the crisis, and that the ECB as an institution focused too much on price stability. This alleged institutional bias was seemingly evident when the ECB raised its policy rate in the face of global financial panic in July 2008 and in 2011 in the face of the Euro Area sovereign debt crisis. However, the decisions had to be reversed in both cases.

In contributing to the debate on the ECB's behaviour in setting the policy rate, this paper focuses on analysis that provides quantitative insights into the aforementioned qualitative argument proposed by commentators by investigating the ECB's monetary policy reaction function during the periods before and after the crisis. However, it is worthwhile to distinguish between monetary policy reaction function and monetary policy strategy. A central bank's monetary policy strategy refers to analysis and criteria determining how monetary policy decisions are made to achieve the underlying stated objective(s). A monetary policy reaction function, on the other hand, outlines the response of the central bank's policy decisions (short-term interest rate changes) to changes in economic variables such as the output gap and inflation. The monetary policy reaction function can thus be thought of as a way of modelling a central bank's monetary policy strategy. Therefore, the focus of this paper is on the ECB's reaction function vis-a-vis its two-pillar monetary policy strategy.

Arguably, the most well-known reaction function is the Taylor rule, introduced by Taylor (1993). However, a similar reaction function was also proposed by Henderson and McKibbin (1993). Taylor's (1993) rule was, specifically, for the US economy, which matches the Fed's dual mandate for optimising both price stability

\footnotetext{
1 The initial strategy adopted by the Governing Council in 1998 regarded monetary analysis as Pillar 1 and the economic analysis as Pillar 2. However, monetary aggregate was downgraded to Pillar 2 from 2003.
} 
and employment. Numerous variations of the reaction functions have been adopted that seek to provide a better fit based on economic theory, empirical works or based on different central banks' mandates. Taylor (1999) discusses some earlier alternative rules, while Nikolsko-Rzhevskyy and Papell (2011) provide an updated discussion.

From a European perspective, Peersman and Smets (1999) demonstrate that a Taylor style rule provides a good fit of an aggregated Euro Area model using data from the period 1979-1997. Other papers have sought to address the differences between the ECB policy and that of the European central banks before the introduction of the Euro, e.g. the Bundesbank. For instance, Faust et al. (2001) concluded that the ECB placed more emphasis on the output gap and less on inflation than the Bundesbank. Gerdesmeier and Roffia (2003) extended this work by incorporating different output gap definitions and a measure of monetary growth. They found that monetary growth is significant in an ECB reaction function and has the effect of reducing the coefficients of the output gap and inflation. Gerdesmeier and Roffia (2003) interpret this as the monetary variable contains additional insight that not fully reflected in forecasts, which is in line with the ECB's cross-checking strategy. Carstensen (2006) identifies various works, which analyse the ECB's behaviour and draw a significant conclusion that, unlike the Taylor-rule analysis of other countries, inflation is often found to be of little or no statistical significance. ${ }^{2}$ Instead, the output gap variable is found to have a strong positive coefficient and statistical significance. In a same vein, Belke and Polleit (2007), who analysed the policy setting behaviours of the ECB and the US Fed, also came to the same conclusion that the ECB placed lighter weight on inflation than output compared to the Fed. Gerlach (2007) suggests that this is because the ECB viewed inflation over the period as of temporary nature, believing that the current output gap is a more important determinant of actual future inflation. However, this explanation might not be entirely satisfactory as the evidence on this is unclear. An alternative explanation was provided by Belke and Polleit (2007), who argue that the lighter weight placed on inflation by the bank might be due to the fact that inflation during the period was very low. This seems to be more plausible as the period prior to the financial crisis was known as the great moderation period due to the low inflation and output volatility recorded.

Gerlach (2007) finds an important distinction between the ECB's reaction function and those of other central banks, in that subjective measure of output such as the European Commission's Economic Sentiment Indicator (ESI) and the ECB's own GDP forecasts have a higher statistical significance than statistically estimations of output gap. Gerlach (2007) also concurs with the findings of Heinemann and Ulrich (2005) that, in addition to other variables, the ECB also responds to the growth of the area's nominal effective exchange rate (NEER).

Reaction functions have also been applied to analyse the ECB's response to the recent crisis. Gorter et al. (2009) compare reaction functions prior to the crisis with functions incorporating a full sample and report that the coefficient on inflation increases in the crisis years. Gerlach and Lewis (2010) look at the issue of setting

$\overline{2}$ These authors include Artus and Wyplosz (2002), Faust et al. (2001), Gali (2001) and Neumann (2001) 
policy rates in the face of the zero-lower-bound (ZLB). They conclude that rates were cut quicker in 2008 and 2009 than suggested by a pre-crisis reaction function. Furthermore, they note that the overnight rate, EONIA, which historically is correlated with the policy rate, was pushed much lower due to the unconventional monetary measures, such as liquidity support implemented by the bank. They conclude that this an evidence that the ECB was acting according to the literature relating to the monetary policy in the face of the ZLB. ${ }^{3}$ Gerlach (2003) and Cukierman and Gerlach (2003) introduce the idea of 'recession aversion', suggesting an asymmetric reaction function in which deviations below potential output are treated more seriously than deviations above.

The empirical analysis undertaken by this paper is concerned with a typical reaction function of the ECB and contributes to the existing literature in two ways. First, in addition to obtaining estimates for the full sample period, the sample is split into pre- and crisis periods using a structural break test. Estimates for the two subsample periods are carried out and compared with the whole period's results. This enables us to separate the analysis into whether the ECB's interest setting behaviour changed during the crisis or not, and which factors were more important in influencing the bank's monetary policy strategy in each. Second, and in contrast to previous studies, the analysis includes both positive and negative rate changes as its dependent variable. This allows for a cross check on previous findings that suggest the ECB's rate setting policy behaviour may be asymmetric, such as only considering the inflation variable during a tightening cycle. Similarly, by separating the dependant variable and the time periods, analysis can be made regarding the extent to which this asymmetry may also have changed.

The rest of the paper is structured as follows. Section 2 discusses "new theory" on international monetary policy inter-dependence as a results of the financial crisis. Section 3 provides a detailed account of the model choice, specifications and the data used in the analysis. Section 4 presents the econometric estimates while Sect. 5 concludes.

\section{2 "New theory": international monetary policy inter-dependence}

Rule-based monetary policy has been adopted by central banks since the late 1980s with particular emphasis on price stability. The Taylor rule, which was introduced above, is the most common reaction function that has typified monetary policy setting behaviour of the banks. Such rules address issues of time inconsistency and promote transparency in monetary policy decisions. Consequently, monetary policy environment was largely determined by domestic macroeconomic outlook with very little consideration to foreign economic developments (Belke et al. 2014). According to Taylor (2013), this was not a problem during the "great moderation" period, from the late 1980 s to the mid-2000s, as the international environment was in equilibrium. He, however, contends that this seemingly balanced situation was

\footnotetext{
${ }_{3}^{3}$ See Reifschneider and Williams (2000) for a detailed discussion on optimal monetary policy in the presence of the ZLB.
} 
perturbed by deviations from the Taylor rule in the US and, subsequently, other countries, where interest rates were held lower than implied by the rule. These deviations were partly blamed for the development of asset price booms and busts, in the US, which led to the Great Recession with very serious consequences for the rest of the world (Taylor 2009). Specifically, the low policy rate in the US led to, among other things, two main developments. First, a depreciation of the dollar, which other countries resisted by also cutting their interest rates in return. Second, it led to the development of greater appetite for riskier activities as businesses sought out investments that yield higher returns. As a result of the crisis, the international financial system was greatly disturbed, and the ability of the central banks to set monetary policy independent of foreign developments was curtailed. Therefore, empirical work that deals with monetary policy during this period needs to address this issue of international interdependence. Belke et al. (2014) have shown that accommodating these "international spill overs" not only has a theoretical justification, but also improves the performance of an estimated Taylor reaction faction for this period as evidenced in the results they reported for the ECB, the Bank of England, The Fed and the Bank of Japan. This paper addresses the issue in Sect. 3.

\section{The empirical methodology}

\subsection{The ordered probit model}

Policy rate changes at the ECB are discrete actions taken by the Governing Council based on a combination of different analysis. The Council's interpretation of this analysis is subjective and, normally, must justify a rate rise of at least 25 bps. The policy rate is thus often left unchanged for long periods, and this leads to the policy rate series highly autocorrelated, with last period's interest rate being the best guess of this period's. To overcome this problem, part of the literature substitutes the policy rate with the overnight interest rate, EONIA, which is the main transmission mechanism for the ECB's policy rate to market rates. However, there are two reasons why using EONIA in its raw form as a dependant variable in this paper might not be suitable. First, this analysis is concerned only with identifying the emphasis placed by the Council on variables when justifying a change in rates, rather than the continuous relationship between macroeconomic variables and the policy rate. Second, the analysis looks at which factors are used to justify rate changes policies during both tightening and loosening cycles. Thus the chosen model needs to allow for splitting the dependent variable into positive and negative policy changes. As such, the ordered-probit model, which is used to model dependant series with discrete changes, is adopted and a variable series is created to signify rate changes. The reason for doing this is that during the crisis period the normal relationship between the EONIA and the policy rate became uncorrelated due to the use of the unconventional policy measures and the greater use of verbal communications adopted by the bank. As such, we may draw incorrect conclusions by focussing solely on the main policy rate. The construction of the alternative 
EONIA variable is explained in the data section. Nevertheless, the EONIA in its actual form is also used in one of the specifications for robustness checks.

In the ordered-probit model, an observed variable, $Y$, changes each period by one of $J$ different discrete amounts. The impetus for the change is represented by a latent level that does not just appear in single time period, but rather is allowed to fluctuate continuously. Once this level, made up of changes in the explanatory variables reaches a certain threshold value, it signifies a rate change. The impetus for rate changes is defined as the difference between the continuous latent level and a lagged value of the observed policy rate, $Y_{t}^{*}-Y_{t-1}$. The latent level is defined in terms of its own changes from period to period, plus some initial level, $Y_{0}^{*}$. A vector of lagged explanatory variables, $\Delta X$ plus a disturbance, $\varepsilon_{t}$, cause changes in the latent level. The model can thus be expressed as:

$$
\Delta Y_{t}^{*}=\Delta X_{t-1}^{\prime} \beta+\varepsilon_{t}
$$

where $Y_{t}^{*}$ represents the policy rate, $X_{t}^{\prime}$ is a vector of explanatory variables and $\varepsilon_{t}$ is an error term. The impetus is denoted by $Z_{t}$ and can be written as the sum of the new pressure for a change and the pressure carried over from the last period and can be represented as:

$$
Z_{t}=\Delta Y_{t}^{*}+\left(Y_{t-1}^{*}-Y_{t-1}\right)
$$

Therefore, changes in the policy rate depend on the value of $Z_{t}$, with direction and scale of changes determined by the set of threshold values based on the pattern of observed rate changes in the data.

\subsection{The ECB strategy and targeted variable developments}

The ECB is governed under the law according to the Maastricht Treaty. Article 105(1) of the Maastricht Treaty states that "the primary objective of the Euro System of Central Banks shall be to maintain price stability". The ECB fulfils this mandate by using a strategy that comprises of a quantitative definition of price stability and the two-pillar approach discussed in Sect. 1 of the paper. The two pillars allow the ECB Governing Council to cross-check the views it infers from both economic and monetary analysis. In a speech in 2005, the former Chief Economist of the ECB, Otmar Issing, underlined the thinking behind this process where he states: "it has been argued that mis-measurement of the output gap in real time has contributed to misguided economic policy decisions" and that "historical experience has shown that an analysis of money and credit developments can provide information in advance of a build-up of asset price overvaluations." As a result of these considerations, Issing stated that the measure of broad monetary aggregates, M3 appears to have predictive power for inflationary pressures at horizons longer than those in other real and financial indicators.

Hence, the aim of the monetary pillar is to anticipate developments that cannot be inferred from real economic variables alone, such as asset price bubbles. Importantly, however, as the ECB has also communicated, it must be able to disentangle shocks in these monetary variables from the underlying trends. For 
instance, over the 2-year period, from November 2001 to October 2003, the annual growth rate of $\mathrm{M} 3$ averaged $7.7 \%$, far above the reference rate of $4.5 \%$. This positive monetary shock could not be explained by developments in traditional monetary determinants, such as output, prices and interest rates alone. However, the ECB's analysis under its monetary pillar suggest that this rise was due to portfolio shifts stemming from a liquidity preference shock. As a result, the ECB constructed an M3 series that accounted for such portfolio shifts, which in turn suggest that monetary developments would not have an adverse effect on future inflation.

Taking these and other previous communications from the ECB into account is important in understanding which variables should be included when analysing the ECB's reaction function. For instance, in addition to the normal M3 variable that Issing and the ECB policy documents refer to, it can also be insightful to analyse the M3 series adjusted for portfolio shifts series, which is referred to above. This series was published by the ECB from January 1999 to July 2008. In addition, the analysis also uses real-time variables, which provide an indication of the information that was available to the ECB Governing Council when it was making policy decisions.

\subsection{The ECB model, data and the empirical strategy}

The historical evolution of the Euro Area policy decisions since the ECB's inception in 1999, along with those of the US Fed and the Bank of England (BoE), are presented in Fig. 1. The figure indicates that the ECB's policy rate started about $2 \%$ pts and $1 \%$ pt, respectively, lower than those of the BoE and the Fed. Over the early 2000s, there is a little correlation between the three. Although each central bank cuts rates sharply after the dot.com bust, by the middle of 2003 they are at very

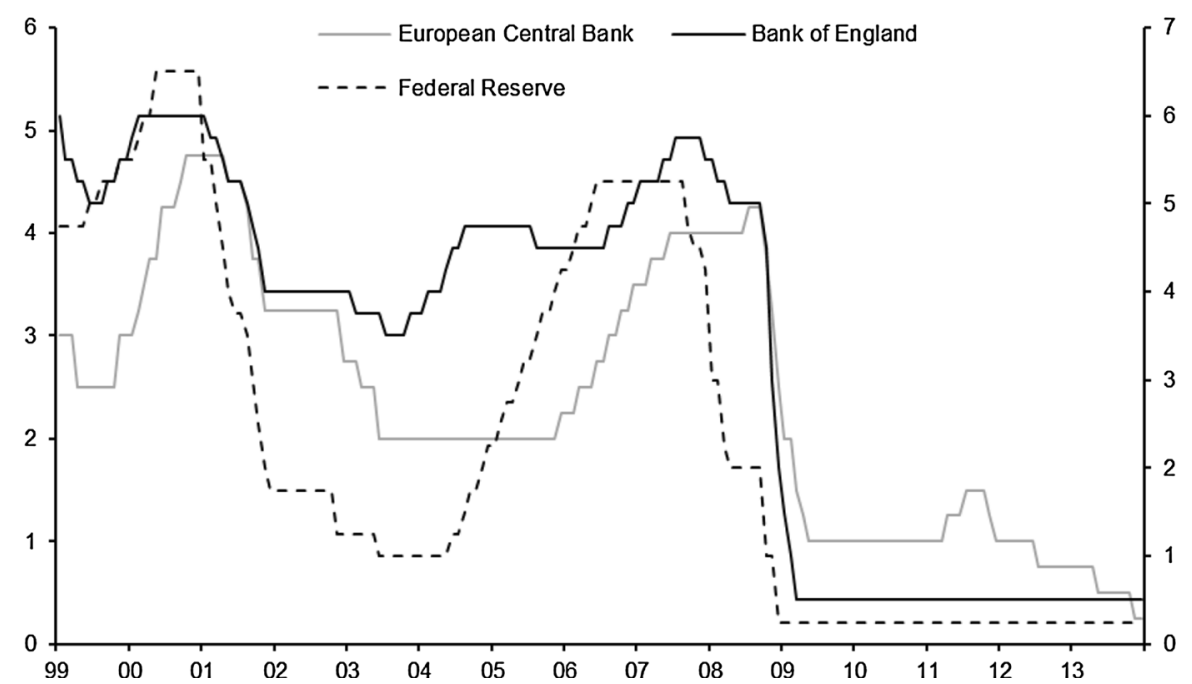

Fig. 1 Policy rates in ECB, Bank of England and the Fed (\%). Source: ECB, Bank of England, Federal Reserve 
different levels. From 2009 to the end of 2013, neither the BoE or the Fed changed its policy rate, but the ECB has adjusted its rates up and down. Table 1 shows 37 months out of 155 recorded changes in the ECB's policy rate during the sample period. A noticeable point is that positive policy rate changes tend to be small, not more than $25 \mathrm{bps}$, rather than negative policy rate changes that are either 25 bps or more (50 bps, and in one case, up to $75 \mathrm{bps}$ ).

Based on the foregoing, the specification of the model follows Dolado et al. (2005) and Gerlach (2007) and takes an ordered-probit model of the ECB's reaction function in the following form:

$$
i_{t}^{P}=\alpha_{1} y_{t}+\alpha_{2} \pi_{t}+\alpha_{3} \mu_{t}+\alpha_{4} \epsilon_{t}
$$

where $i_{t}^{P}$ represents the Governing Council's policy rate target, $y_{t}$ denotes a measure of potential growth, $\pi_{\mathrm{t}}$ is inflation, $\mu_{t}$ represents money growth and $\varepsilon_{t}$ is the nominal effective exchange rate (NEER), while the constant is suppressed. The coefficients $\alpha_{i}$ are positive with the exception of $\alpha_{4}$, which is negative due to the nature of the NEER variable, as discussed in the data section. Judd and Rudebusche (1998) argue that an interest rate smoothing parameter should be included in the reaction function, which takes the form of:

$$
i_{t}-i_{t-1}=\beta_{0}\left(i_{t}^{*}-i_{t-1}\right)+\beta_{1} \Delta i_{t-1}+e_{t}
$$

where $e_{t}$ is a residual and once again the constant is omitted. Equation (4) states that the change in the policy rate in the current period is set as some amount, $\beta_{0}$, of the difference between the current and the target rate as well as taking into account any changes in the policy rate in the last period. The implication is that those responsible for setting the policy rate avoid large, successive changes. Hence, $0<\beta_{0}<1$ and $\beta_{1}<0$. Combining Eqs. (3) and (4) gives:

$$
i_{t}^{*}-i_{t-1}=\delta_{1} y_{t}+\delta_{2} \pi_{t}+\delta_{3} \mu_{t}+\delta_{4} \epsilon_{t}-\beta_{0} i_{t-1}+\beta_{1} \Delta i_{t-1}+e_{t}
$$

where $\delta_{i}=\alpha_{i} \beta_{0}$ and $i_{t}^{*}$ is the unobserved, latent variable. What is actually observed is the discrete policy rate change which depends on the position of the latent level relative to set of threshold values. These threshold values, $\tau_{i}$, take into account the observed changes in the policy rate over the period, ranging from $\tau_{1}$ to $\tau_{5}$, representing five thresholds as follows:

Table 1 Changes in the Policy Rate: January, 1999-December, 2013. Source: The ECB

\begin{tabular}{lcccc}
\hline & \pm 25 bps & \pm 50 bps & $+/ 75-$ bps & Total \\
\hline Increase & 16 & 2 & 0 & 18 \\
Decrease & 9 & 9 & 1 & 19 \\
Total & 23 & 11 & 1 & 37 \\
\hline
\end{tabular}




$$
\Delta i_{t}= \begin{cases}-0.75 \% & \text { if } i_{t}^{*}-i_{t-1} \leq \tau_{1} \\ -0.50 \% & \text { if } \tau_{1}<i_{t}^{*}-i_{t-1} \leq \tau_{2} \\ -0.25 \% & \text { if } \tau_{2}<i_{t}^{*}-i_{t-1} \leq \tau_{3} \\ 0 & \text { if } \tau_{3}<i_{t}^{*}-i_{t-1} \leq \tau_{4} \\ +0.25 \% & \text { if } \tau_{4}<i_{t}^{*}-i_{t-1} \leq \tau_{4} \\ +0.50 \% & \text { if } \tau_{5}<i_{t}^{*}-i_{t-1}\end{cases}
$$

where $\Delta i_{t}$ is the latent continuous random variable that causes the adjustment while $\tau_{i}$ are the thresholds, which the latent variable should exceed in order to provoke change in the value of $i_{t}$. Equations (5) and (6) give the final specification of the model is estimated.

As shown in Table 1, the policy rate changes that took place during the sample period are grouped into $\pm 25, \pm 50$ and $\pm 75 \mathrm{bps}$. There are eighteen positive changes and nineteen negative ones, giving a total of 37 policy changes that were carried out. The ECB's main monetary policy instrument is the official policy rate, also known as the Repo rate. The Repo rate is used as a transmission mechanism to steer short-term market rates such as the overnight rate, EONIA. A discrete variable was constructed to represent changes in the Repo rate, which varies from -3 for a -75 bps change to +2 for a +50 bps change. ${ }^{4}$ Also incorporated are a lagged change in the policy rate variable in line with interest rate smoothing theory and the lagged policy rate level to address issues of serial autocorrelation in the residuals. In addition, a variable based on cumulative 25 bp changes in the EONIA was also constructed. The reason for doing that is because the relationship between the EONIA and the Repo rate broke down during the crisis period. This breakdown can be seen in Fig. 2, which presents the Repo rate and EONIA for the sample period.

One of the variables used in the estimation of the Taylor rule is the output gap. However, there are debates on how best to calculate this measure. ${ }^{5}$ As noted by Gerlach (2007), the ECB national accounts data are generally not released until several months after policy decisions have been made. The ECB typically refer to available survey data, notably the Economic Sentiment Index, ESI. This measure shows a strong correlation with output calculations of the Euro Area. Given these factors, this paper uses two different economic activity measures. First, it uses the ESI in the estimation as in Gerlach (2007). The ESI variable is sourced from the European Commission. ${ }^{6}$ The indicator is an aggregate of surveys from all the Euro Area member states based on five sectors. These are industry, services, consumer, construction and retail trade. Figure 3 depicts the relationship between the ESI and the real GDP growth. Second, we also incorporate an output gap measure in another specification of the model. The measure of the output gap is taken from the OECD database. Using the OECD's output gap measure has two advantages over calculating one applying some statistical methods, such as the Hodrick-Prescott Filter as mostly done. First, its global publication ensures that it is likely to be a

\footnotetext{
4 The choice of values for the scale does not affect the estimates.

5 For a further discussion, see Billmeier (2004).

6 Accessed January 2014.
} 


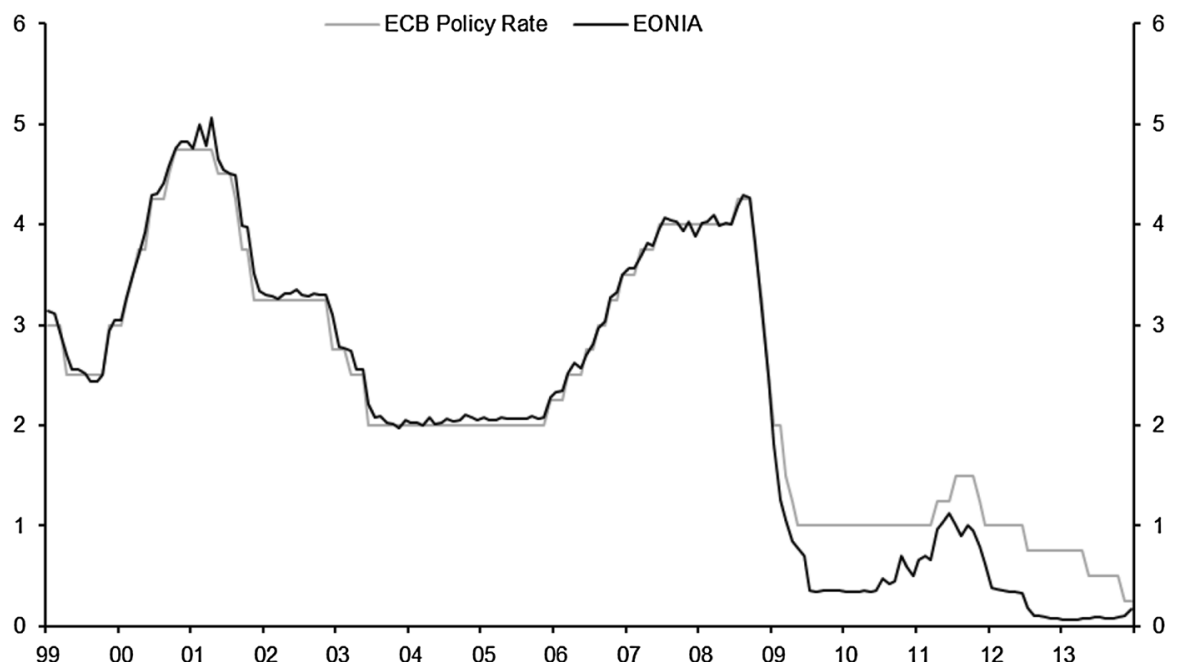

Fig. 2 ECB policy rate and EONIA (\%)

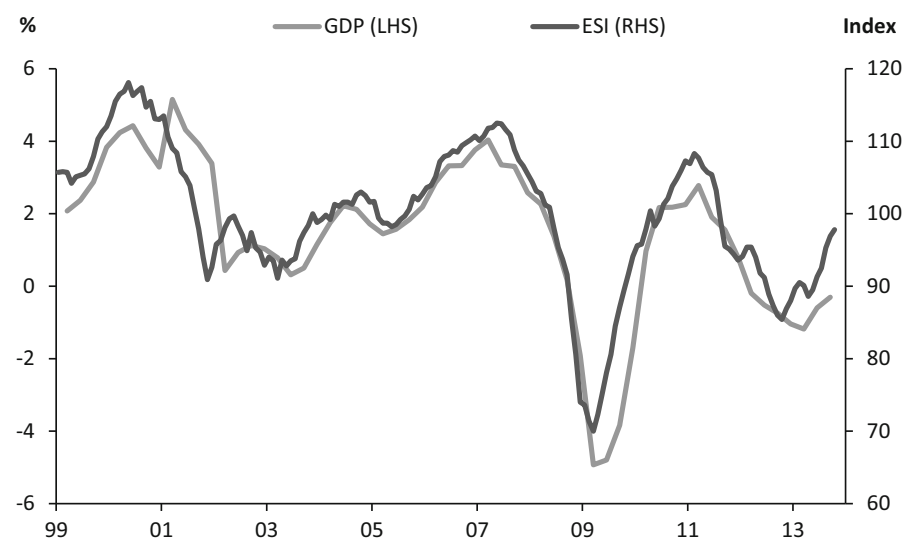

Fig. 3 The economic sentiment index and the Euro GDP. Source: European Commission and Eurostat

robust measure ensuring that miscalculation does not influence our estimates. Second, it ensures this work is easily replicable. Figure 4 presents this variable for the sample period.

As part of our preliminary work, a few different model specifications, incorporating various inflation variables such as core HICP and HICP forecasts from the Survey of Professional Forecasters, were analysed. However, as the results did not differ significantly, we only publish those with the main HICP inflation variable, which is the official ECB mandated target. The Governing Council emphasises the M3 broad measure of the monetary base as its benchmark monetary variable. This is included as a 3 mMA year-on-year growth rate in line with ECB 


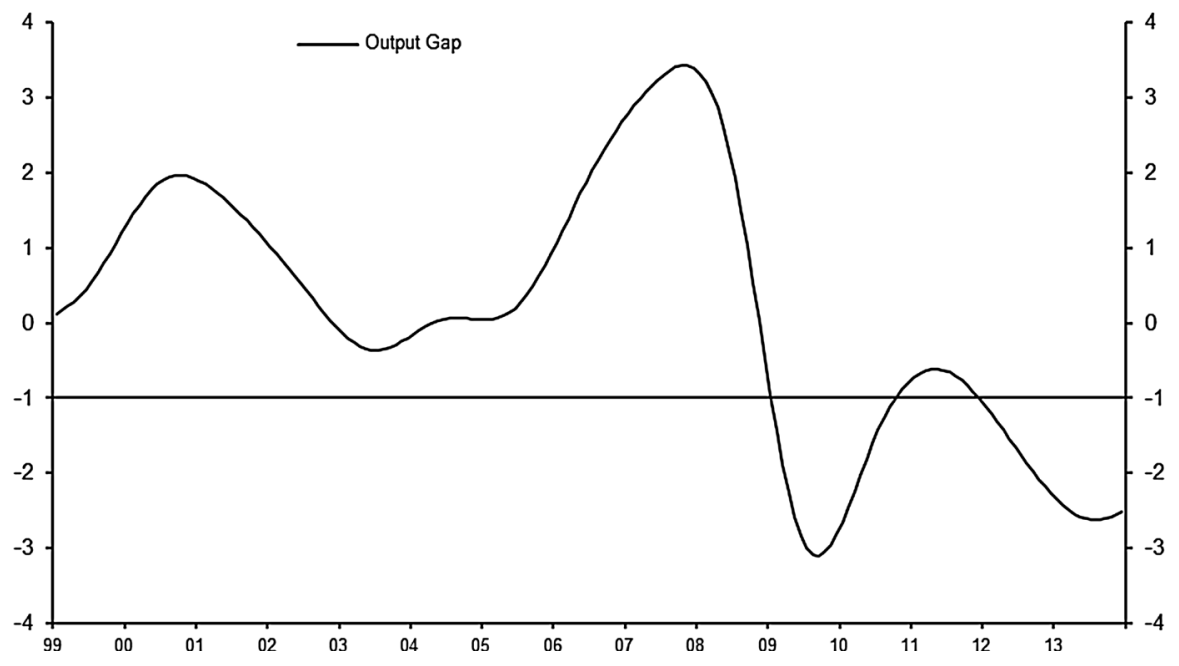

Fig. 4 Output gap (\% of GDP). Source: OECD

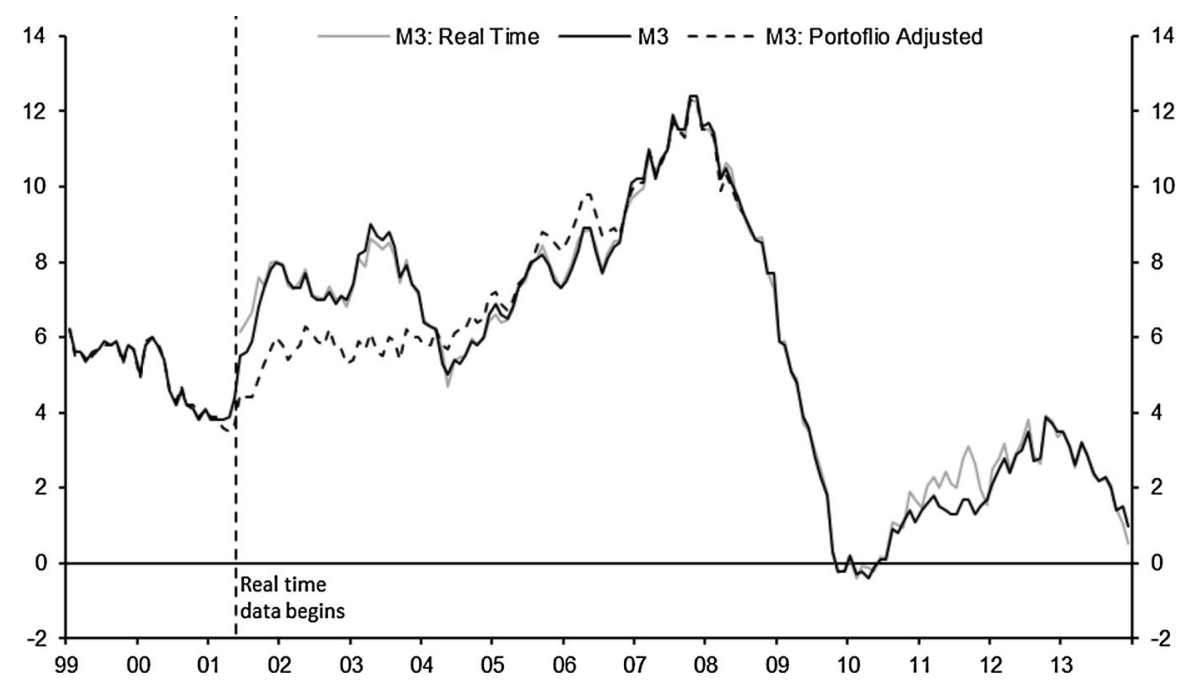

Fig. 5 M3Real Time, M3 and M3-Portfolio Adjusted (\%). Source: ECB, Euro area business cycle network

communications. Figure 5 shows various measures of M3 including the M3 portfolio adjusted discussed above. The nominal effective exchange rate (NEER) is incorporated as suggested by Heinemann and Ullrich (2005) who find that the variable is statistically significant. The year-on-year per cent growth rate is taken to avoid issues with structural changes over the time and it is defined such that a positive growth rate represents appreciation, which should lead to less import price pressures. Hence, the estimates should show a negative relationship between the 


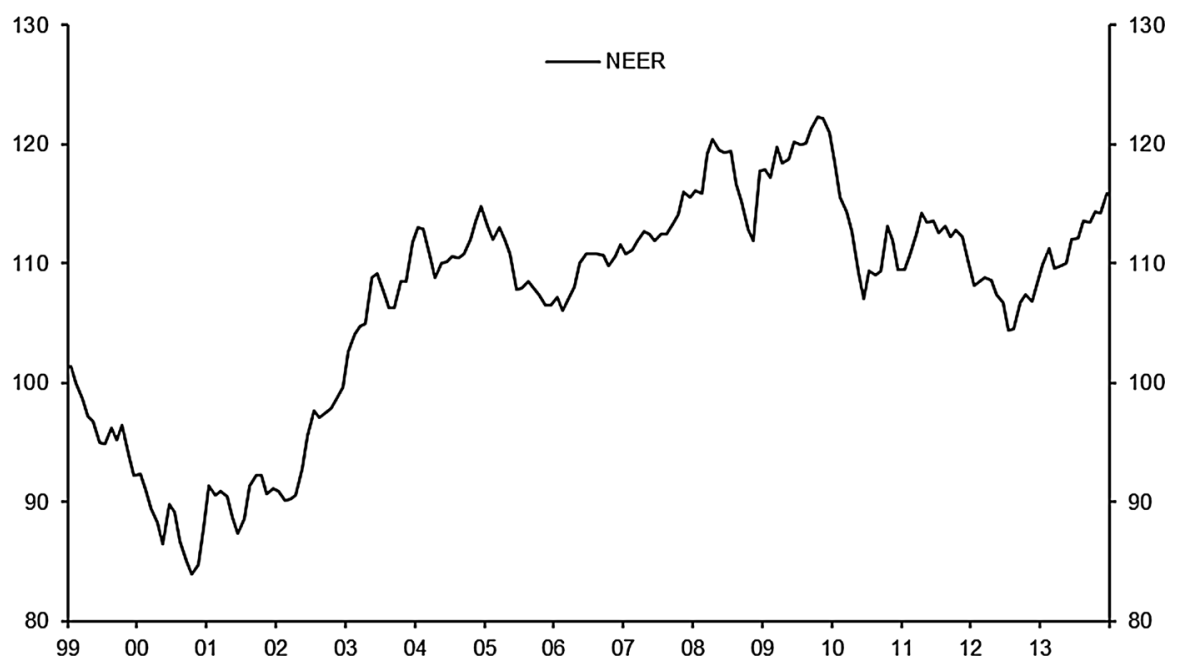

Fig. 6 The Euro nominal effective exchange rates (NEER). Source: ECB

NEER growth and positive policy rate changes. The NEER variable is depicted in Fig. 6. Each variable was incorporated with a lag to reflect the extent to which data are available to the ECB when setting the rates. The ESI and HICP variables are both available with a 1-month lag. Monetary growth and the output gap measures are available with a 2-month lag, and 1-month lag is applied to the NEER variable to avoid issues of simultaneity. Table 2 presents the various sources and the definitions of the variables used in the paper.

As discussed in Sect. 2, domestic monetary policy has increasingly become influenced by international economic activities as a result of international imbalances, which Taylor (2013) attributes to deviations from the Taylor rule that began in the US in the early-2000s and subsequently in other countries. Following Belke and Klose (2013), who show that accounting for the international inter-dependence in central banks reaction function is essential, we include foreign interest rates (represented by the Fed rate and the Bank of England policy rate ${ }^{7}$ ) into the model.

Another issue worth noting is that monetary policy during the financial crisis takes place near the zero-lower-bound. To circumvent this issue, Belke and Klose (2013) use a measure of the central bank's balance sheet, which explicitly captures the effects of the unconventional monetary policy such as the quantitative easing. In order to address this and as an additional robustness check, this paper uses the real interest rate. ${ }^{8}$ Figure 7 demonstrates relationship between the nominal and the real interest rates, which indicates that the latter was more variable than the former.

\footnotetext{
7 The use of the Fed rate as a proxy for foreign interest rates is conventional in the literature due to the dominant role of the US in the global economy. The Bank of England policy rate is used in another specification as the UK is the closer geographically, and as a result more integrated economically in terms of trade.

${ }^{8}$ Results with the real interest rates are not significantly different from the reported one. Hence, they are not reported in the paper, but are available on request.
} 
Table 2 Description of the variables

\begin{tabular}{lll}
\hline Variable & Source & Expected coefficient \\
\hline ECB repo rate & ECB & $\mathrm{n} / \mathrm{a}$ \\
EONIA & ECB & $\mathrm{n} / \mathrm{a}$ \\
HICP & Eurostat & Positive \\
Core HICP & Eurostat & Positive \\
Money supply-M3 & ECB & Positive \\
Nominal effective exchange rate & ECB & Negative \\
Output gap & Eurostat \& author's calculations & Positive \\
Federal funds policy rate & Federal Reserve & Positive \\
Bank of England policy rate & Bank of England & Positive \\
\hline
\end{tabular}

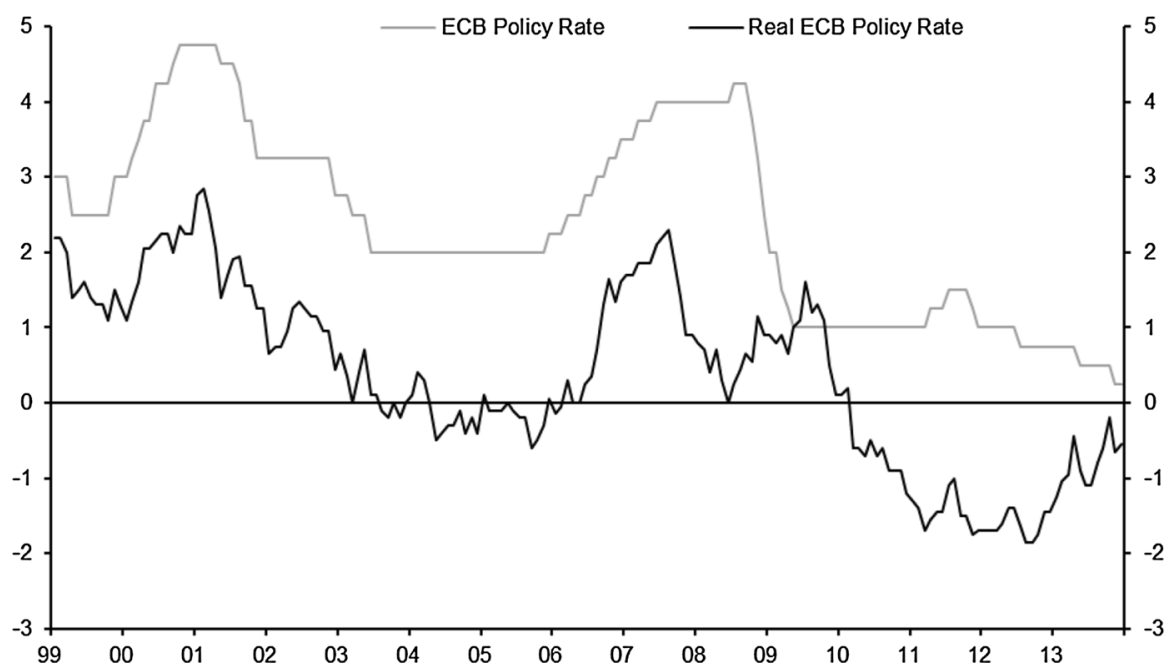

Fig. 7 The real and nominal ECB policy rate (\%). Source: ECB

\subsection{Pre- and financial crisis periods}

A key part of the analysis comes from splitting the sample into pre-crisis and crisis periods. To identify the most suitable breakpoint for the two periods, the Bai-Perron multivariate structural break tests were used and the results are reported in Table 3. ${ }^{9}$ As shown in the table, the identified breakpoint is August 2007, with a $95 \%$ confidence interval of June 2006 to December 2008. This coincides with the period that commentators commonly attribute as the start of the financial crisis ${ }^{10}$ when money markets in the US started showing signs of stress. This was chosen to split the sample into the pre- and crisis periods. As such, in the remainder of this paper,

\footnotetext{
9 The break has been modelled both in constant and trend. However, results for the latter indicate that the variable is nether significant nor improve the overall results. Hence, the break in the trend was dropped.

${ }^{10}$ See Taylor (2009) for full discussion.
} 
Table 3 The Bai-Perron structural break tests

\begin{tabular}{llllll}
\hline \multicolumn{2}{l}{ Coefficients } & Break date & $95 \% \mathrm{CI}$ & $\mathrm{F}(\mathrm{m})$ & $\mathrm{F}\left(\mathrm{m}^{-1}\right)$ \\
\hline$\beta_{1}$ & $3.14^{* *}$ & $2007: 08$ & $2006: 06-2008: 12$ & 92.76 & 55.79 \\
$\beta_{2}$ & $0.47^{* *}$ & & & & \\
\hline
\end{tabular}

$\beta_{1}$ and $\beta_{2}$ refer to the mean before and after the break and ** signifies rejection at $5 \%$. Both BIC and LWZ are significant for the identified break

the period of January 1999 to August 2007 is referred to as the "pre-crisis", while the period from September 2007 to December 2013 is called the "crisis" period.

\section{Discussions of the estimated results}

Table 4 reports the results obtained by estimating the model specified in Eq. (6). In addition to the coefficient estimates, z-statistics and an indication of statistical significance are also reported in the table. For each specification, the McFadden pseudo- $\mathrm{R}^{2}$ is given, which provides an indication of likelihood for each specification, with a greater value representing a higher likelihood. As this is an orderedprobit model, the coefficients are interpreted as a change in the explanatory variables inducing a higher probability of the dependent variable changing. Comparing coefficients between explanatory variables is not appropriate due to the scale differences between them; for instance, the ESI ranges from 70.1 to 118.6 while HICP ranges from -0.6 to $4.0 \%$.

The results in Table 4 show the results obtained for the whole time period using the both the main Repo rate and the EONIA as a dependent variable. The first two columns in each section report results of the models that utilise all policy rate changes as the dependant variable with the ESI and the output gap (OG) as measures of economic activity, respectively. The remaining 4 columns in each section represent the results for positive and negative policy changes during the whole period. Therefore, for each type of dependant variable - that is, all rate changes, positive rate changes and negative rate changes - there are four specifications. Thus, there are 12 separate specifications, represented by model (1)-(12) in the table.

The results from model (1) indicate that the coefficients for M3 and economic activity have the expected signs and are statistically significant, but the coefficient for inflation has the wrong sign and is not statistically significant. The coefficients in model (2) are all significant, but again the coefficient of inflation is of incorrect sign, and the same is true for M3. Of model (1) and model (2), the McFadden $\mathrm{R}^{2}$ suggests that model (1) provides a better fit. This is supported by the fact that the monetary coefficient estimate in model (2) is also, counter-intuitively, negative. Moreover, the estimates for model (1) are consistent with the findings of other authors, in that the ESI activity measure is found to be positive and significant, while the HICP measure is found to be statistically insignificant. For example, Gerlarch (2007) who used data for the period prior to the financial crisis, found this to be the case. Gali (2001) also found no systematic relationship between interest rate and inflation in the Euro 


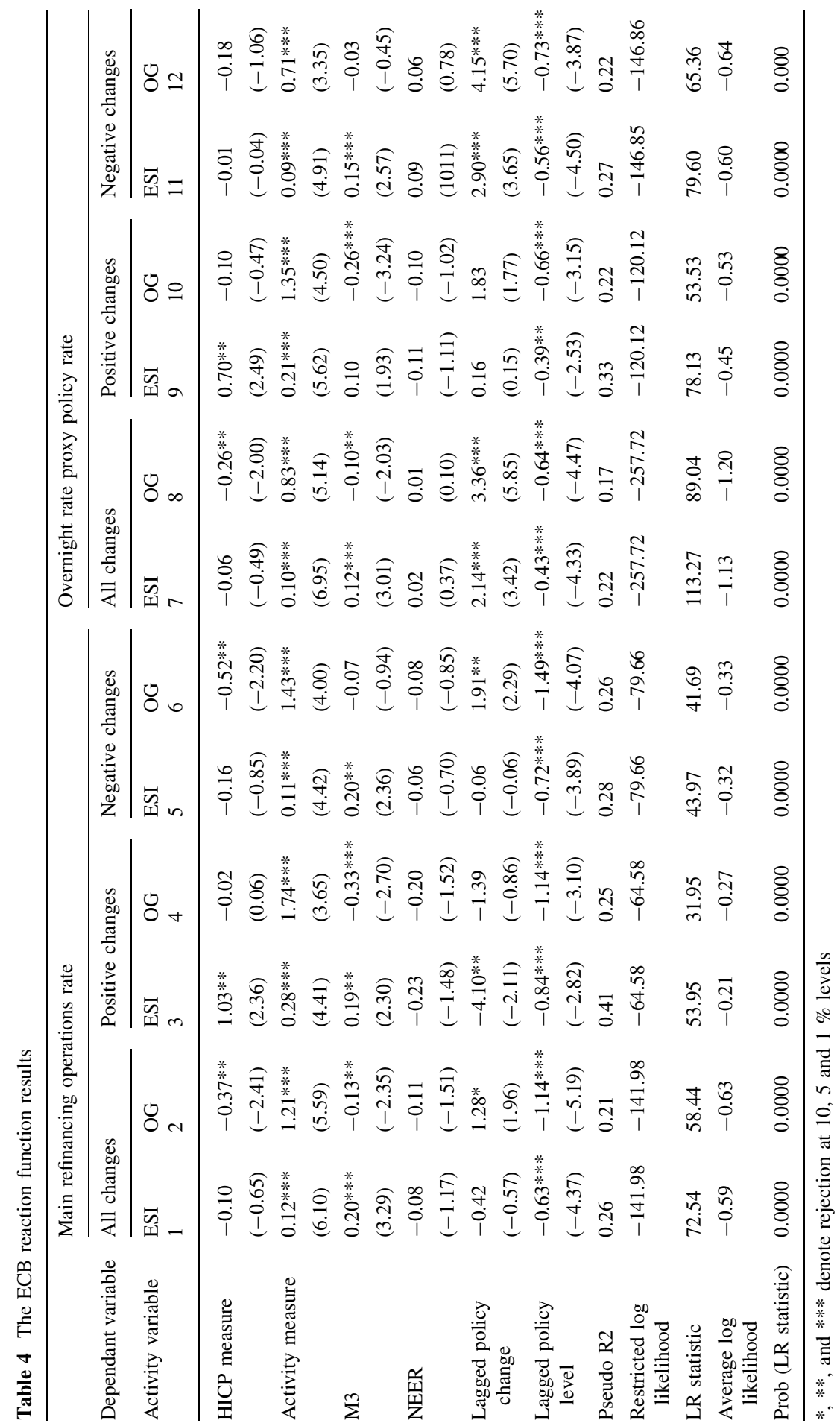


Area, and similar results were reported by Carstensen (2006) and Belke and Polleit (2007). The estimates for models (7) and (8), utilising the EONIA-constructed dependent variable, show that there is little difference between the results irrespective of the dependent variables.

Given the better fit provided by the ESI specification, the remaining discussion focuses on models that use this variable as a measure of economic activity. Columns (3) and (5) show the results obtained when the dependant variable uses either positive or negative rate changes only. The most noticeable difference between these two is that inflation coefficient is only positive and statistically significant in the positive rate rises. This suggests that inflation is an important factor in determining raising interest rate during the period, but might not be a significant factor in rate cutting decisions. The activity measure is significant in both casesalthough of a lower magnitude in the rate cutting model-while monetary growth is both significant and almost of the same magnitude in each case. It is worth noting that in each of the specifications discussed so far the exchange rate variable is found to be insignificant, which is inconsistent with other studies such as Gerlach (2007), Gali (2001) and Carstensen (2006). Again, the results when using the EONIA as dependent variables, shown in columns (9) and (11), are similar.

Since it is clear that the specifications with the ESI produce better results than those that used the output gap, the latter specifications for the pre-crisis and crisis periods models are not reported in the paper. ${ }^{11}$ Consequently, Table 5 presents six specifications for the pre-crisis period, and the same six specifications for the crisis period. Considering only the pre-crisis period, model (1), with all the rate changes, reveals that inflation is significant and positive, unlike under the whole time period model. However, like the whole time period model, the ESI and the monetary variables have positive and significant coefficients. ${ }^{12}$

Compared to the whole period models, when looking only at the pre-crisis period the coefficient estimates for the positive and negative rate change specifications differ. The main difference is that the inflation variable is significant only in the negative rate change specification, shown in column (3) of Table 5. That contrasts with the whole time period specifications, in which inflation was significant only in the positive policy changes model. The monetary variable is also only significant when considering negative policy rate changes, rather than only positive changes. The coefficient on the monetary variable for all policy changes for pre-crisis model (1) is significant, albeit, relatively low. Splitting the changes into positive and negative show that the coefficient is only marginally significant (at $10 \%$ ) for negative policy changes during the pre-crisis period (using the Repo rate) while it is insignificant for the rest of the specifications. This might not be surprising as the variable was not meant to take care of credit and debt developments, but to indicate factors derived from the Quantity Equation. As was the case with the whole period

\footnotetext{
${ }^{11}$ However, they are available on request. The results are consistent with the ones reported in Table 4.

12 All the models were re-estimated using the revised M3 variable, which accounted for portfolio shifts. This variable only affects short time periods as it was discontinued in 2008. The affected time period is the pre-crisis one. However, the results are not significantly different from the one that used M3. The only difference is that the M3 coefficient became insignificant in the pre-crisis in the negative rate changes model. The results are not reported, but available on request.
} 


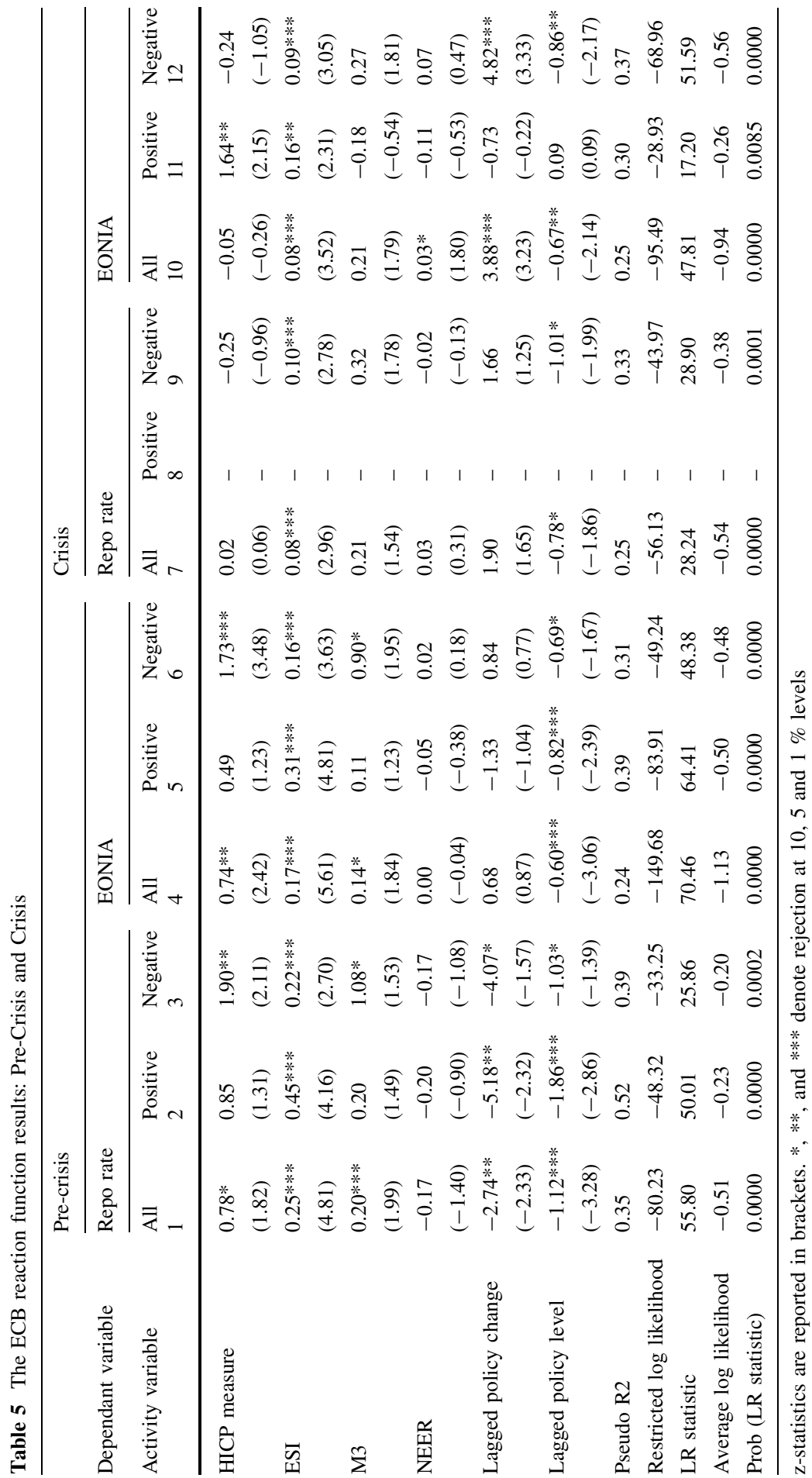


model, there is little difference between the models that use the EONIA variable or the Repo rate.

The remaining six models, (7)-(12), cover the crisis period that starts from 2007:08 to 2013:12. Lack of rate rises over this time period means that it is in model that the constructed EONIA variable becomes useful. Model (7) is the main, all-policy rate changes specification for the crisis period. In this case, only the ESI is significant, and is of the expected positive sign. The result is similar when EONIA is used as a dependent variable, as shown in model (10). In the rate rise only model, shown in column (11), the HICP coefficient is positive and significant, as is the ESI coefficient. However, in the negative change specification only the ESI variable is statistically significant.

Overall, the model estimates offer some interesting insights into the ECB policy rate setting. From the whole time period model, the estimates in Table 4 suggest that the ECB's rate setting behaviour does not conform to, at least, one of the requirements of its mandate, inflation targeting, due to the statistical insignificance of inflation variable. However, this changes when modelling only the pre-crisis period. That is, between 1999:01 and 2007:07 the HICP, the ESI and the monetary growth variables coefficients were all positive and statistically significant. On that basis, it could be concluded that the ECB appeared to be abiding by its operational principles during the pre-crisis period. However, separating the policy changes into positive and negative changes during the pre-crisis period shows that the coefficient values and statistical significance are higher for rate cuts than rate rises. That could suggest that the ECB was more averse to low inflation than worried about high inflation during the period. This contrasts with the behaviour seen over the crisis, when positive rate changes were influenced by both the HICP and the ESI. That would seem somewhat paradoxical, given that the ECB should have had more support for keeping rates lower than necessary during times of economic stress than during the pre-crisis period. However, some sort of analysis on the extent to which inflation expectations were factor over those two periods would be useful in order to make a definite conclusion.

Splitting the analysis into pre- and crisis periods has provided some useful insight, but as monetary policy has taken place near the zero-lower-bound since the crisis, estimates with nominal interest rate such as the Repo or the EONIA should be treated with caution. To check the extent to which this is a problem, the analysis in this paper used a real interest rate variable as the dependent variable. This was chosen as an alternative to the central banks' balance sheet measure used by Belke and Klose (2013). The results are reported in Table 6, which indicate that inflation is insignificant for all the specification. This is consistent with other studies that found inflation in the ECB reaction function was either marginally significant or insignificant at all (see for example, Carstensen 2006; Belke and Polleit 2007). The coefficients for the monetary aggregates are also insignificant in each model. Although the economic activity measure is highly significant across both the preand the crisis specifications, but it is of wrong sign in the crisis specification. This helps to explain why it is not significant in the whole period model. Importantly, the Pseudo R-squared are much lower than those using the nominal policy rates, which suggests that neither of the three models using the real policy rate changes explains 
Table 6 The ECB reaction function results-real interest rate

\begin{tabular}{lccc}
\hline & \multicolumn{2}{c}{ Real main refinancing operations rate dummy } & \\
\cline { 2 - 4 } & Whole period & Pre-crisis & Crisis \\
\hline HICP measure & 0.02 & $0.53^{*}$ & 0.13 \\
Activity measure & 0.13 & 1.76 & 0.41 \\
& 0.00 & $0.07^{* * *}$ & $-0.05^{* * *}$ \\
M3 & 0.14 & 2.91 & -2.71 \\
& 0.05 & 0.13 & 0.05 \\
NEER & 1.45 & 1.58 & 0.52 \\
& 0.02 & 0.06 & 0.02 \\
Lagged policy change & 0.31 & 0.74 & 0.23 \\
Lagged policy level & 0.64 & -0.29 & 1.12 \\
& 1.06 & -0.35 & 1.16 \\
Pseudo R2 & -0.13 & -0.26 & -0.36 \\
Restricted log likelihood & -1.26 & -1.39 & -1.18 \\
LR statistic & 0.01 & 0.08 & 0.08 \\
Average log likelihood & -220.99 & -117.41 & -96.82 \\
Prob (LR statistic) & 6.16 & 20.71 & 15.25 \\
\hline Z-stastics are & -1.22 & -1.06 & -1.15 \\
& 0.4047 & 0.0021 & 0.0183 \\
\hline
\end{tabular}

z-statistics are reported in brackets. *,**, and $* * *$ denote rejection at 10,5 and $1 \%$ levels

the ECB's policy rate setting behaviour well. This is likely to be the case because the real interest rates show a great variation due to fluctuations in inflation, which is evident in Fig. 7.

As discussed in Sect. 2, domestic monetary policy has become increasingly interdependent during the crisis period. Taylor (2013) argues that during the period running up to the financial crisis, international monetary equilibrium has been perturbed. Supporting this, Belke et al. (2014) show that accounting for international interdependence is necessary. To explicitly account for this, we undertake analysis that includes foreign interest rates among the independent variables. Specifically, we use the Fed rate and the Bank of England policy rate. The results these specifications are reported in Table 7. These show that the foreign policy rates are not significant for most of the specifications, and the rest of the results are not significantly different from those in Table 5. The main exception is when we consider only positive policy rate changes. In this case, both the Fed and the Bank of England policy rates become statistically significant.

Part of the literature on monetary policy reaction function has used real-time series in order to address the forward looking nature of monetary policy setting. Although, this is somewhat captured by the ESI, this paper also uses real-time series accessed from the Euro Area Business Cycle Network to complement the estimation and also to act as additional robustness checks. The real time data started in full in 2002, which limits the number of specifications that can be estimated with them 


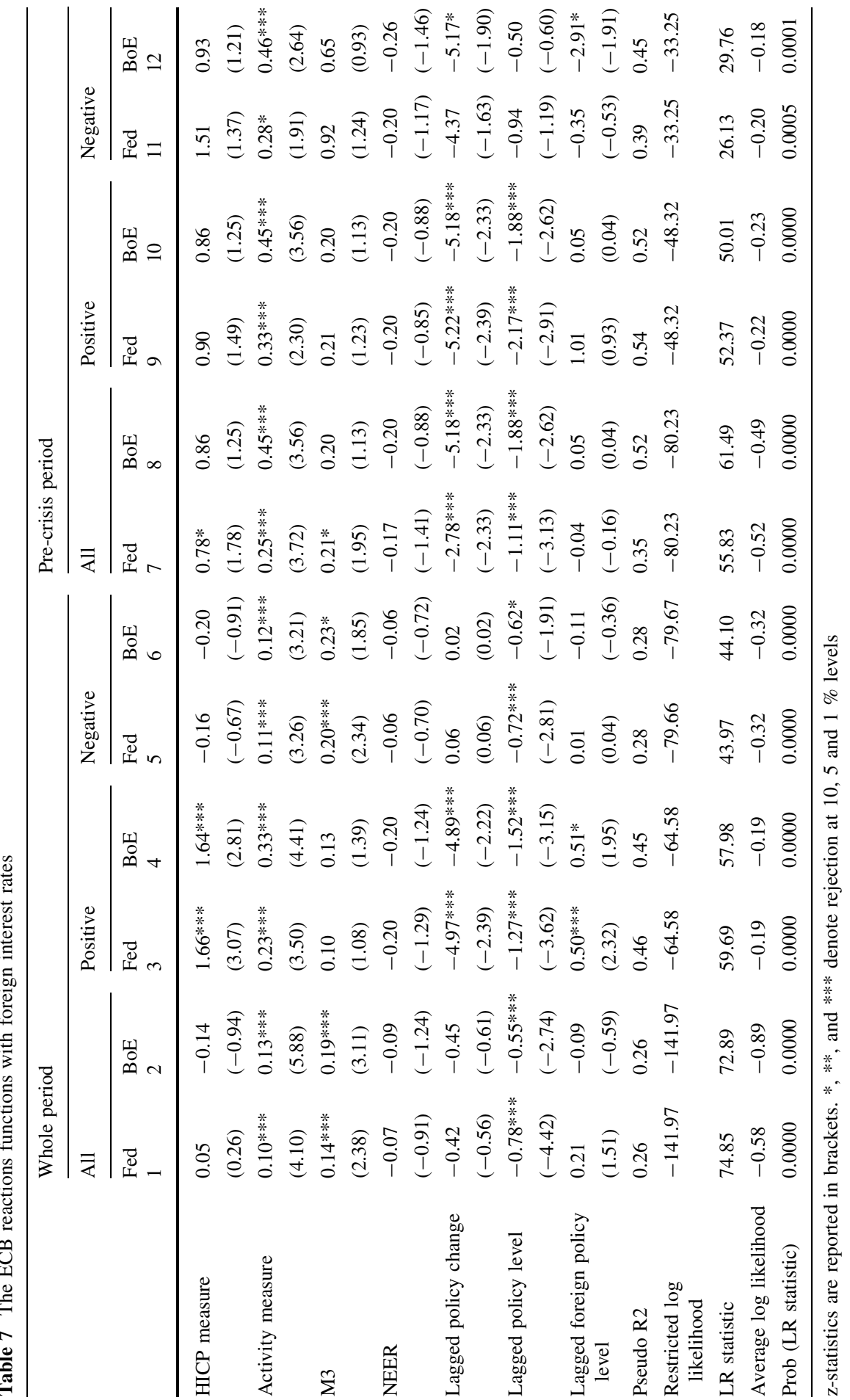


using the probit model. We are, however, able to estimate models for the whole period, pre- and crisis periods, but unable to split the changes into positive and negative changes. The results from the estimations are not significantly different from the ESI models reported in Table $5 .^{13}$

Overall, the complete results seem to suggest that the ECB did abide by its twopillar monetary strategy in the pre-crisis period, given the significance and correct theoretical sign of the HICP, the ESI and the monetary growth variables. However, the results from the pre-crisis, rate rise only model cast doubt on this, given that only the activity variable is significant in this model. This is particularly so when it comes to contractionary monetary policy, given that, unlike inflation, the future path of monetary growth is less likely to be affected by the activity variable. This gives some support to some commentators' argument that the bank did very little to curb credit growth in the Euro Area during the period before the crisis. The policy changes during the crisis period suggest that the ECB may have placed too much emphasis on inflation as demonstrated by the large coefficient on the HICP variable in the model utilising only positive policy rate changes as the dependent variable.

It could be conjectured that maintaining low interest rates during the pre-crisis period could be attributed to ideological factors. For instance, Belke and Cui (2010) portend that the incumbent governments' ideology (whether belonging to the left or right) has significant effect on monetary policy of OECD countries. They report that central banks that are less independent tend to have low policy rates under the leftwing governments. Since the ECB is an amalgamation of various national central banks, attempts by the ECB to accommodate various governments of different ideological lineages may be reflected in the estimated results.

\section{Conclusions}

This paper investigated the interest rate setting behaviour of the ECB for the period between 1999 and 2013. The sample period was split into pre- and crisis periods by using the Bai-Perron structural break test. The paper estimated models using all rate changes as the dependent variable, as well as using only rate rises or rate cuts. This was done for the whole sample period as well as for the two sub-periods. The results for the whole period suggest that the ECB's policy changes were not, on the whole, influenced by inflation. This is consistent with other previous work in Carstensen (2006) and Belke and Polleit (2007).

However, results from the pre-crisis and crisis periods, as well as results covering models with the dependant variable split into positive and negative rate cycles, add some extra insight. Over the whole time period, when considering only rate rises, inflation becomes significant and of the correct theoretical sign. This is interesting, but could point to a number of things. For instance, it could be that bouts of low inflation were considered to be of a temporary nature and thus did not deem a rate response, or due to the fact that inflation was generally low during the period. Belke and Polleit (2007) have also found that the ECB had lower weight on inflation

\footnotetext{
13 The results are not reported, but available on request.
} 
relative to other central banks. Belke and Potrafke (2012) argue that government ideological inclination is a factor in central banks' monetary policy decisions as they found this is the case in the OECD countries: central banks that are less independent under the leftwing governments tend to run more expansionary monetary policy. As the ECB is an amalgam of different central banks, it may try to accommodate divergent views, which might be the reason. Secondly, it could be that the long periods of low inflation have affected the results. For instance, after the crisis, given that rates were already very low and thus unlikely to be lowered further, it may seem that the ECB did not respond to low inflation.

Splitting the model into separate time periods also adds some support to the idea that already low rates affected the results. That's because, when considering only rate cuts, in the pre-crisis period the model does find inflation to be statistically significant and of the correct coefficient, but despite periods of below target inflation in the crisis period, the crisis-model coefficients are not statistically significant. Hence, in this case, although we have tested using real time data, a further area of research could be to include explicit ECB forecasts in order to make the reaction function specifications more forward-looking, or to find a way in which to account for the rapid lowering of interest rates in response to the financial crisis.

Finally, for robustness checking, various specifications of the models were estimated. These include specifications with different inflation variables, using of real interest rates, foreign interest rates and real time data. However, none of these results has significantly affected the results.

Acknowledgments We are grateful to the editor and acknowledge constructive and useful comments received from two anonymous reviewers.

Open Access This article is distributed under the terms of the Creative Commons Attribution 4.0 International License (http://creativecommons.org/licenses/by/4.0/), which permits unrestricted use, distribution, and reproduction in any medium, provided you give appropriate credit to the original author(s) and the source, provide a link to the Creative Commons license, and indicate if changes were made.

\section{References}

Artus P, Wyplosz C (2002) La politique monétaire de la Banque centrale européenne, Rapport du Conseil d'analyse économique, la Documentation française, Paris

Belke A, Cui Y (2010) US-Euro area monetary policy interdependence: new evidence from Taylor rule based VECMs. World Econ 33(5):778-797

Belke A, Klose J (2013) Modifying Taylor reaction functions in presence of the zero-lower-bound: evidence for the ECB and the federal reserve. Econ Model 35:515-527

Belke A, Polleit T (2007) How the ECB and the US fed set interest rates. Appl Econ 39(17):2197-2209

Belke A, Potrafke N (2012) Does government ideology matter in monetary policy? A panel data analysis for OECD countries. J Int Money Finance 31(5):1126-1139

Belke A, Beckmann J, Dreger C (2014) The Relevance of International Spillovers and Asymmetric Effects in the Taylor Rule, DIW Discussion Paper No. 1416/2014, Deutsches Institut für Wirtschaftsforschung, Berlin 
Billmeier A (2004) Ghostbusting: which output gap measure really matters? [online]. IMF Working Paper, No. WP/04/146. http://www.imf.org/external/pubs/ft/wp/2004/wp04146.pdf. Accessed 15 Mar 2012

Carstensen K (2006) Estimating the ECB Policy Reaction Function. Ger Econ Rev 7(1):1-34

Cukierman A, Gerlach S (2003) The Inflation Bias Revisited: Theory and Some International Evidence. CEPR Discussion Paper No. 3761. London, Centre for Economic Policy Research. http://www.cepr. org/pubs/dps/DP3761.asp. Accessed 3 Mar 2012

Dolado JJ, Maria-Dolores R, Naveirad M (2005) Are monetary-policy reaction functions asymmetric? The role of nonlinearity in the Phillips curve. Eur Econ Rev 49:485-503

Faust J, Rogers JH, Wright JH (2001) An empirical comparison of Bundesbank and ECB monetary policy rules. Board of Governors of the Federal Reserve System, International Finance Discussion Papers, No. 705

Gali J (2001) Monetary Policy in the Early Years of EMU. In: Proceedings of the Function of EMU: The Challenge of the Early Years, March 21-22 2001, Brussels, European Commission. Mimeo, CREI, Universitat PompeuFabra

Gerdesmeier D, Roffia B (2003) Empirical Estimates of Reaction Functions for the Euro Area. ECB Working Paper, No. 206

Gerlach S (2003) Recession aversion, output and the Kydland-Prescott Barro-Gordon model. Econ Lett 81:389-394

Gerlach S (2007) Interest rate setting by the ECB, 1999-2006: words and deeds. Int J Cent Bank 3:1-45

Gerlach S, Lewis J (2010) The Zero Lower Bound, ECB Interest Rate Policy and the Financial Crisis. DNB Working Papers No. 254, Netherlands Central Bank, Research Department

Gorter J, Jacobs J, de Haan J (2009) Negative rates for the Euro area. Cent Bank 20(2):61-66

Heinemann F, Ullrich K (2005) Does It Pay to Watch Central Bankers Lips? The Information Content of ECB Wording. ZEW Discussion Paper, No. 05-70

Henderson DW, McKibbin WJ (1993) A comparison of some basic monetary policy regimes for open economies: implications of different degrees of instrument adjustment and wage persistence, International Finance Discussion Papers No. 458, Board of Governors of the Federal Reserve System (U.S.)

Judd JP, Rudebusche GD (1998) Taylor's Rule and the Fed: 1970-1997. Fed Reserve Bank San Franc Econ Rev 3:3-16

Neumann MJM (2001) The Euro: major policy implications for Europe and the global economy. Pac Econ Rev 6:301-312

Nikolsko-Rzhevskyy A, Papell D (2011) Taylor's rule versus Taylor rules. SSRN: http://ssrn.com/ abstract=1826363. Accessed 25 Feb 2012

Peersman G, Smets F (1999) The Taylor rule: a useful monetary policy benchmark for the euro area? Int Finance 2:85-116

Reifschneider D, Williams J (2000) Three lessons for monetary policy in a low-inflation era. J Money Credit Bank 32(4):936-966

Taylor JB (1993) Discretion versus policy rules in practice. Carnegie-Rochester Conference Series on Public Policy, vol 39, pp 195-214

Taylor JB (1999) The robustness and efficiency of monetary policy rules as guidelines for interest rate setting by the European central bank. J Monet Econ 43(3):655-679

Taylor JB (2009) The financial crisis and the policy responses: an analysis of what went wrong. NBER Working Paper no. 14631

Taylor JB (2013) International monetary coordination and the great deviation, Paper prepared for the Session on International Policy Coordination, American Economic Association Annual Meetings, San Diego, California, January 